\title{
IMPLEMENTASI PEDAGOGICAL CONTENT KNOWLEDGE (PCK) DALAM MENINGKATKAN KEMAMPUAN KOGNITIF SISWA
}

\author{
Ai Nur Solihat, Universitas Siliwangi \\ ainursolihat@unsil.ac.id \\ Suminawati, Universitas Siliwangi \\ suminawati@unsil.ac.id \\ Edi Fitriana Afriza, Universitas Siliwangi \\ edifitriana@unsil.ac.id
}

\begin{abstract}
ABSTRAK
Dengan menggunakan metode penelitian analisis deskriptif, diperoleh hasil penelitian mengenai gambaran pedagogical content knowledge (PCK), kemampuan kognitif siswa dan pengaruh PCK merupakan tujuan dari penelitian ini. Subjek penelitian melibatkan siswa kelas XI SMA Negeri se-Kota Tasikmalaya. Teknik analisis data menggunakan analisis deskriptif untuk mengetahui gambaran PCK dan kemampuan kognitif siswa, dan analisis regresi linier sederhana untuk mengetahui pengaruh PCK terhadap kemampuan kognitif siswa. Berdasarkan hasil penelitian, PCK guru ekonomi dan kemampuan kognitif siswa SMA Negeri Kota Tasikmalaya berada pada kondisi sedang. Hasil penelitian yang diperoleh adalah terdapat pengaruh PCK terhadap tingkat kemamppuan kognitif siswa. Artinya, jika terjadi peningkatan pada PCK guru maka kemampuan kognitif siswa juga akan meningkat.
\end{abstract}

Kata Kunci: Pedagogical Content Knowledge, Kemampuan Kognitif.

\begin{abstract}
This study aims to find out an overview of pedagogical content knowledge (PCK), students 'cognitive abilities and the influence of PCK on students' cognitive abilities. The research method used is descriptive analysis. The population in this study were students of senior high school class XI Tasikmalaya. The sampling technique was used simple random sampling. The data analysis technique is used descriptive analysis to the description of PCK and students 'cognitive abilities, and simple linear regression analysis to determine the effect of PCK on students' cognitive abilities. Based on the results of the study, PCK of economic teachers and the cognitive abilities of students of Tasikmalaya Senior High School were in moderate condition. The results of this study are that there is an effect of PCK on students' cognitive ability level. That is if there is an increase in teachers' PCK, the students' cognitive abilities will also increase.
\end{abstract}

Keywords: Pedagogical Content Knowledge, Cognitive Abilities. 


\section{PENDAHULUAN}

Kemampuan internal seseorang yang secara unik dalam berpikir, memecahkan suatu masalah, dan mengambil keputusan dapat disebut sebagai kemampuan kognitif. Kemampuan unik dalam berpikir tersebut diinterpretasikan melalui analisa yang tajam, tepat, dan akurat sehingga sering dikenal pula dengan control tingkat tinggi (executive control).

Kemampuan kognitif tertinggi dari Gagne (Yamin, 2008) diilustrasikan sebagai strategi kognitif berupa analisis, sintesis dan evaluasi yang dapat dipelajari baik oleh siswa maupun guru. Kemampuan ini dapat dilatih melalui pemberian bahan atau materi pelajaran sehingga siswa dapat memecahkan masalah, baik dalam kelas maupun dalam kehidupan sehari-hari. Pemberian informasi awal pada materi pelajaran di kelas merupakan cikal bakal bagi siswa dalam mengembangkan diri, dan sekaligus menindaklanjutinya untuk memacu kemampuan berpikir mereka.

Memasuki era globalisasi banyak tuntutan ketersediaan sumber daya manusia yang memiliki kompetensi supaya dapat bersaing secara terbuka baik secara lokal maupun global. Kompetensi tersebut merupakan kekuatan utama bagi industri dalam menghasilkan keunggulan secara komprehensif dan inovatif. Upaya membangun kualitas sumberdaya diperlukan adanya kemampuan berpikir sebagai bentuk dari sebuah proses pembelajaran, oleh karena itu dalam memuncakki pencapaiannya harus didukung dengan motivasi tinggi dan kemampuan berpikir yang baik agar kualitas lulusan pendidikan yang dihasilkan optimal.

Kemampuan berpikir tingkat tinggi yang kreatif, produktif dan inovatif dapat menjadi salah satu keunggulan sumber daya Indonesia agar mampu bertahan dalam persaingan global. Kemampuan berpikir tersebut dinilai dapat mengatasi masalah pertumbuhan penduduk, pengangguran, tanggung jawab sosial, keberagaman ketenaga kerjaan, etika, kemajuan teknologi dan ilmu pengetahuan, dan gaya hidup merupakan tantangan yang saling terkait.

Realitas masih menggambarkan minimnya kualitas sumber daya manusia Indonesia yang didukung data TIMSS (Trends in International Match Science Survey) dari Global Institute (2007) dengan melaporkan rendahnya kemampuan berpikir tingkat tinggi siswa dari (Kementrian Pendidikan dan Kebudayaan, November 2012). Kemampuan siswa Indonesia dalam mengerjakan soal berpikir tingkat tinggi dan advance (reasoning) hanya 5\%. Hal ini tentu sangat jauh lebih rendah jika dibandingkan dengan siswa Korea yang pada saat itu sudah $71 \%$ di antaranya dapat mengerjakan soal yang sama. Bila dilihat dari sudut pandang yang lain, 78\% siswa Indonesia baru dapat mengerjakan soal-soal tingkat rendah (knowing), sedangkan siswa Korea hanya $10 \%$. Pada tahun 2009, hasil survey PISA juga melaporkan masih rendahnya kemampuan siswa Indonesia dalam penguasaan materi pelajaran. Hampir seluruh siswa Indonesia hanya menguasai pelajaran sampai level 3, dibandingkan negara lain sudah banyak yang mencapai level 4 hingga level 6 .

Melalui asumsi pada dasarnya seluruh manusia diciptakan sama, pandangan dari beberapa hasil survey tersebut akan bermuara pada ketidaksesuaian materi yang diberikan dengan tuntutan zaman. Perubahan kurikulum dari Kurikulum 2006 menjadi Kurikulum 2013 (kurtilas) yang 
secara pasti lebih mendorong kepada penguatan reasoning sehingga kemampuan siswa dalam berpikir tingkat tinggi dapat ditumbuhsuburkan serta dapat membentuk manusia yang lebih produktif, kreatif, inovatif serta berkarakter. Kurikulum 2013 saat ini sangat memungkinkan untuk dapat meningkatkan kompetensi siswa dalam berpikir tingkat tinggi, serta dapat menghasilkan insan yang produktif, kreatif, inovatif, dan berkarakter.

Kurikulumm2013 mengimplementasikan pendidikan karakter dan dapat diintegrasikan pada setiap mata pembelajaran yang terdapat dalam kurikulum. Pada setiap bidang studi, materi pembelajaran yang sekait dengan norma perlu dikembangkan, dieksplisitkan, dan dihubungkan dengan konteks kehidupan sehari-hari. Unsur kurikulum, perencanaan dan proses pembelajaran, mekanisme evaluasi, kualitas hubungan, pengelolaan pembelajaran, pengelolaan sekolah, pelaksanaan pengembangan diri, pemberdayaan sarana dan prasarana, pembiayaan, serta etos kerja seluruh warga dan lingkungan sekolah terlibat dalam penerapan kurikulum 2013.

Keterlibatan komponen-komponen pada penerapan kurikulumn2013 dapat dipadukan dalam sebuah sistem pembelajaran yang menjadi inti dari proses pendidikan secara keseluruhan dengan guru sebagai pemegang peranan utama. Guru professional tidak hanya ditunjukkan atau dibuktikan dengan sertifikat profesional melainkan harus ditunjukkan oleh kinerja sebagai seorang pendidik. Guru saat ini dituntut tidak hanya menguasai materi (content) dan strategi pengajaran, tetapi harus memiliki pemahaman dan kapabilitas dalam memadukan pengetahuan tentang materi, kurikulum, belajar, pengajaran, dan siswa. Pengetahuan tersebut kini dikenal sebagai pengetahuan konten pedagogi (pedagogical content knowledge).

Pedagogical Content Knowledge (PCK) dideskripsikan sebagai hasil penggabungan antara pengetahuan materi (content knowledge) dan pengetahuan pembelajaran (pedagogical knowledge) dalam satu paket utuh seorang pengajar. Shuell dan Shulman (Eggen \& Kauchak, 2010) menyatakan bahwa PCK sebagai pengetahuan metode pembelajaran yang efektif untuk mendeskripsikan materi, serta pegetahuan yang membuat materi terasa mudah atau sulit dipelajari.

PCK dibentuk dari content knowledge dan pedagogical knowledge. Yang termasuk pada content knowledge yaitu pengetahuan konsep, teori, ide, kerangka berpikir, metode pembuktian dan bukti. Sementara pedagogical knowledge berbicara tentang pengetahuan pengelolaan kelas, penugasan, perencanaan proses pembelajaran dan pembelajaran siswa (Depaepe, 2018; Shulman, 1986). Sampai saat ini PCK telah banyak ditelit. Hasil penelitian PCK banyak memberikan dampak yang positif terhadap kegiatan pembelajaran dan berimplikasi pada cara guru mengajar dengan materi yang diajarkan.

\section{METODE PENELITIAN}

Penelitian ini menggunakan metode survey deskriptif yang bertujuan untuk memperoleh gambaran PCK dan kemampuan kognitif siswa. Data diperoleh dari hasil pengisian kuesioner skala likert oleh siswa dengan teknik analisis data menggunakan regresi linier sederhana untuk mengetahui pengaruh PCK terhadap kemampuan kognitif siswa. Populasi meliputi 1569 siswa 
dengan teknik pengambilan sampel proportionate random sampling sebanyak 320 orang.

\section{HASIL PENELITIAN DAN PEMBAHASAN}

Data penelitian dianalisis dengan bantuan SPSS untuk mengetahui kemampuan kognitif siswa dengan skor terendah 35, tertinggi 67, rata-rata (mean) 48,08; nilai tengah (median) 47,50 dan standar deviasi 5,96. Untuk $\mathrm{n}=$ 320 tersebar dalam 9 kelas dengan Rentang data 32 dan interval kelas masingmasing 3. Distribusi frekuensi kemampuan kognitif siswa dapat dirangkum dalam Tabel 1.

Tabel 1. Distribusi Frekuensi Variabel Kemampuan Kognitif Siswa

\begin{tabular}{cccc}
\hline No & Interval & Frekuensi & Frekuensi Relatif (\%) \\
\hline 1 & $35-37$ & 11 & 3,44 \\
2 & $38-40$ & 15 & 4,69 \\
3 & $41-43$ & 46 & 14,37 \\
4 & $44-46$ & 66 & 20,63 \\
5 & $47-49$ & 60 & 18,75 \\
6 & $50-52$ & 53 & 16,56 \\
7 & $53-55$ & 34 & 10,62 \\
8 & $56-58$ & 16 & 5,00 \\
9 & $\geq 59$ & 19 & 5,94 \\
\hline & Jumlah & $\mathbf{3 2 0}$ & $\mathbf{1 0 0}$ \\
\hline
\end{tabular}

Tabel 1 terlihat bahwa kemampuan kognitif siswa pada kelas interval 44 sampai 46 adalah yang terbesar frekuensinya. Kemampuan kognitif siswa dapat digolongkan menjadi kategori kecenderungan tinggi, sedang, dan rendah. Data kemampuan kognitif siswa ini diperoleh dengan menggunakan kuesioner (angket) skala likert 1 sampai dengan 5. Rata-rata ideal kemampuan kognitif siswa 51 dengan standar deviasi ideal 5,33. Dari perhitungan tersebut dapat dibuat kategori kecenderungan seperti pada Tabel 2.

Tabel 2. Distribusi Kecenderungan Variabel Kemampuan Kognitif Siswa

\begin{tabular}{cccccc}
\hline No & Skor & F & $\begin{array}{c}\text { Frekuensi } \\
\text { Relatif }(\%)\end{array}$ & $\begin{array}{c}\text { Frekuensi } \\
\text { Kumulatif }\end{array}$ & Keterangan \\
\hline 1 & $\mathrm{X} \geq 56,33$ & 35 & 10,94 & 10,94 & Tinggi \\
2 & $45,67 \leq \mathrm{X}<56,33$ & 193 & 60,31 & 71,25 & Sedang \\
3 & $\mathrm{X}<45,67$ & 92 & 28,75 & 100 & Rendah \\
\hline & Jumlah & $\mathbf{3 2 0}$ & $\mathbf{1 0 0}$ & & \\
\hline
\end{tabular}

Tabel 2. menunjukkan kecenderungan kemampuan kognitif siswa. Terdapat 35 orang siswa atau sebesar 10,94 persen siswa berada pada kategori tinggi, 193 orang siswa atau sebesar 60,31 persen berada pada kategori sedang dan 92 orang siswa atau sebesar 28,75 persen berada pada kategori rendah. Berdasarkan data tersebut nampak bahwa sebagian besar siswa telah memenuhi indikator kemampuan kognitif seperti keterampilan intelektual, strategi kognitif, kemampuan verbal, keterampilan motorik dan sikap. 
Data PCK juga dianalisis menggunakan SPSS dengan skor terendah 98, tertinggi 209, rata-rata (mean) 156,48, nilai tengah (median) 157, dan standar deviasi 19,99. Untuk $n=320$ diperoleh 10 kelas dengan rentang data 11 dan kelas interval masing-masing 12. Distribusi frekuensi PCK dapat di lihat pada Tabel 3.

Tabel 3. Distribusi Frekuensi Variabel Pedagogical Content Knowledge

\begin{tabular}{cccc}
\hline No & Interval & Frekuensi & Frekuensi Relatif (\%) \\
\hline 1 & $98-110$ & 8 & 2,50 \\
2 & $111-123$ & 14 & 4,38 \\
3 & $124-136$ & 25 & 7,81 \\
4 & $137-149$ & 59 & 18,44 \\
5 & $150-162$ & 92 & 28,75 \\
6 & $163-175$ & 67 & 20,94 \\
7 & $176-188$ & 38 & 11,87 \\
8 & $189-201$ & 14 & 4,37 \\
9 & $\geq 202$ & 3 & 0,94 \\
\hline & Jumlah & $\mathbf{3 2 0}$ & $\mathbf{1 0 0}$
\end{tabular}

Berdasarkan Tabel 3 menunjukkan bahwa frekuensi terbesar PCK berada pada kelas interval $150-162$. PCK juga dapat digolongkan dalam 3 kategori kecenderungan tinggi, sedang, dan rendah. Data PCK diperoleh dari kuesioner (angket) skala likert 1 sampai dengan 5. Rata-rata ideal PCK 153,5 dengan standar deviasi ideal 18,5. Berdasarkan perhitungan tersebut dapat dibuat kategori kecenderungan seperti pada Tabel 4.

Tabel 4. Distribusi Kecenderungan Variabel Pedagogical Content Knowledge

\begin{tabular}{cccccc}
\hline No & Skor & F & $\begin{array}{c}\text { Frekuensi } \\
\text { Relatif (\%) }\end{array}$ & $\begin{array}{c}\text { Frekuensi } \\
\text { Kumulatif }\end{array}$ & Keterangan \\
\hline 1 & $\mathrm{X} \geq 172$ & 73 & 22,81 & 22,81 & Tinggi \\
2 & $135 \leq \mathrm{X}<172$ & 203 & 63,44 & 86,25 & Sedang \\
3 & $\mathrm{X}<135$ & 44 & 13,75 & 100 & Rendah \\
\hline & Jumlah & $\mathbf{3 2 0}$ & $\mathbf{1 0 0}$ & & \\
\hline
\end{tabular}

Kecenderungan pedagogical content knowledge (PCK) digolongkan dalam tiga kategori kecenderungan yaitu tinggi, sedang, dan rendah. Sebagian besar siswa atau sebanyak 203 orang siswa $(63,44 \%)$ memiliki persepsi terhadap pedagogical content knowledge (PCK) guru berada dalam kategori sedang. Sedangkan sisanya sebanyak 73 orang siswa $(22,81 \%)$ memiliki persepsi terhadap pedagogical conten knowledge (PCK) berada dalam kategori tinggi, dan sebanyak 44 orang siswa $(13,75 \%)$ berada dalam kategori rendah. Artinya, sebagian guru ekonmi sudah memiliki pemahaman wawasan dan landasan kependidikan, pemahaman terhadap peserta didik, pengembangan kurikulum atau silabus, perencanaan pembelajaran, pelaksanaan pembelajaran yang mendidik dan dialogis, pemanfaatan teknologi pembelajaran, evaluasi hasil belajar, dan pengembangan peserta didik untuk mengaktualisasikan berbagai potensi yang dimiliki.

Salah satu tujuan dari penelitian ini adalah untuk mengetahui seberapa besar pengaruh pedagogical content knowledge (PCK) terhadap kemampuan 
kognitif siswa. Dari hasil uji statistic menggunakan Aplikasi SPSS 23 diperoleh koefisien korelasi $(\mathrm{R})$ variabel PCK terhadap kemampuan kognitif sebesar 0.386 artinya variabel PCK memiliki hubungan (berkorelasi) sebesar 38,6\% terhadap kemampuan kognitif siswa. Sedangkan koefisien determinasi $\left(\mathrm{R}^{2}\right)$ sebesar 0,149 menunjukkan bahwa bahwa pedagogical content knowledge (PCK) berpengaruh terhadap kemampuan kognitif siswa sebesar 14,9 persen. Hasil ini menunjukkan bahwa kemampuan kognitif dipengaruhi oleh seberapa tinggi tingkat pedagogical conten knowledge (PCK). Semakin tinggi tingkat PCK yang dimiliki oleh guru maka akan semakin tinggi tingkat kemampuan kognitif siswa, dan sebaliknya. Dimensi PCK dalam penelitian ini meliputi konten pedagogik yang harus dimiliki guru yaitu pemahaman wawasan dan landasan kependidikan, pemahaman terhadap peserta didik, pengembangan kurikulum atau silabus, perencanaan pembelajaran, pelaksanaan pembelajaran yang mendidik dan dialogis, pemanfaatan teknologi pembelajaran, evaluasi hasil belajar, dan pengembangan peserta didik untuk mengaktualisasikan berbagai potensi yang dimiliki.

Pengujian terhadap pengaruh pedagogical content knowledge (PCK) terhadap kemampuan kognitif siswa, dilakukan pengujian regresi linier sederhana dengan menggunakan program SPSS. Pedagogical Content Knowledge (PCK) memiliki korelasi sebesar 38,6 persen terhadap kemampuan kognitif siswa, sedangkan varians kemampuan kognitif siswa dapat dijelaskan oleh pedagogical content knowledge (PCK) sebesar 14,9\%. Adapun persamaan regresinya dapat dirumuskan sebagai berikut :

\section{$\bar{F}=30,040+0,115 X$}

Dari persamaan regresi tersebut diperoleh hasil bahwa kemampuan kognitif dapat dijelaskan dengan ataupun tanpa adanya pengaruh dari pedagogical content knowledge (PCK). Uji hipotesis dilakukan melalui uji t pada taraf signifikansi $95 \%$ dengan hasil bahwa pedagogical content knowledge (PCK) berpengaruh signifikan terhadap kemampuan kognitif siswa.

Kemampuan berpikir sangat diperlukan sebagai bentuk hasil dari proses pendidikan, dimana dalam proses pendidikan merupakan upaya pengkondisian siswa. Bila upaya pengkondisian itu kurang mendukung pencerahan atau pengembangan penalaran, serta kemampuan berpikir yang baik, maka akan melahirkan lulusan pendidikan yang kurang optimal. Padahal dalam era globalisasi seperti sekarang ini menuntut ketersediaan sumber daya manusia yang berkualitas yang memiliki daya saing secara terbuka, yang bisa bersaing baik secara lokal maupun secara global. Sumber daya manusia tidak lagi dianggap sebagai pelengkap semata, akan tetapi sudah menjadi kekuatan utama bagi industri dalam menghasilkan keunggulan dalam konteks yang lebih komprehensif, dan inovatif.

Proses pembelajaran merupakan inti dari proses pendidikan, dimana guru memiliki peranan yang paling penting dalam proses belajar mengajar ini. Guru merupakan pekerjaan profesi dimana seorang guru dituntut memiliki keahlian dalam pengajaran. Keberhasilan dalam pembelajaran salah satunya ditentukan oleh guru. Kompetensi pedagogik guru merupakan kompetensi utama yang harus dimiliki guru dalam melaksanakan proses pembelajaran yang efektif dan dinamis. Sebagaimana diungkapkan dalam Casey (2007) bahwa : 
"The focus of such a program is providing instruction and practice to build pedagogical knowledge and skills, with a lesser focus on content knowledge. The expectation is that, at completion of the program, the preservice teachers will have the knowledge, skills, and attitudes needed to be good beginning teachers."

Salah satu kemampuan dasar yang harus dimiliki guru adalah kemampuan dalam merencanakan dan melaksanakan proses belajar mengajar. Kemampuan ini membekali guru dalam melaksanakan tugas dan tanggung jawabnya sebagai pengajar. Belajar dan mengajar terjadi pada saat berlangsungnya interaksi antara guru dengan siswa untuk mencapai tujuan pengajaran. Sebagai proses belajar, belajar dan mengajar memerlukan perencanaan yang seksama, yakni mengkoordinasikan unsur-unsur tujuan, bahan pengajaran, kegiatan belajar mengajar, metode dan alat bantu mengajar serta penilaian/evaluasi. Pada tahap berikutnya adalah melaksanakan rencana tersebut dalam bentuk tindakan atau praktek mengajar. Lebih lanjut pengetahuan tersebut dinamakan sebagai pengetahuan konten pedagogi atau pedagogical content knowledge (PCK). Sebagaimana diungkapkan oleh Shulman dalam Eggen dan Kauchak (2012) bahwa pedagogical content knowledge is an understanding of how to represent topics in ways that make them understandable to learners, as well as an understanding of what makes specific topics easy or hard to learn.

\section{SIMPULAN}

Hasil penelitian menunjukkan bahwa pedagogical content knowledge (PCK) memiliki pengaruh terhadap kemampuan kognitif siswa. Adapun saran dari hasil penelitian ini, bagi guru ekonomi diharapkan dapat meningkatkan kemampuan pedagogiknya agar dapat meningkatkan kemampuan kognitif siswa. Sedangkan saran bagi peneliti selanjutnya, agar dilakukan penelitian reflikasi dengan menambah variabel-variabel lain yang mempengaruhi kemampuan kognitif siswa yang tidak diteliti pada penelitian ini. Sehingga akan diketahui variabel mana yang paling mempengaruhi kemampuan kognitif siswa dan dapat ditingkatkan.

\section{DAFTAR RUJUKAN}

Casey, C.E. \& Ruth A.C. (2007). Teacher Education Program Admission Criteria and What Beginning Teachers Need to know to be Successful Teachers. Canadian Journal of Educational Administration and Policy, issue \#67.

Depaepe, J.K. (2018). General pedagogical knowledge, self-efficacy and instructional practice: Disentangling their relationship in pre-service teacher education. Teaching and Teacher Education. Vol. 69, pp. 177190.

Kementrian Pendidikan dan Kebudayaan. (November 2012). Pengembangan Kurikulum 2013. Tersedia [Online] : http://www.kemdikbud.go.id. 
Eggen P., \& Kauchak, Don. (2012). Strategi dan Model Pembelajaran Mengajarkan Konten dan Keterampilan Berpikir Edisi Keenam. Jakarta: PT. Indeks Permata Puri Media.

Shulman, L.S. (1986). Those Who Understan: Knowledge Growth in Teaching. Educational Researcher, Vol. 15, No. 2 (Feb., 1986), pp. 4-14. Tersedia [online]: http://www.jstor.org/stable/1175860 .

Yamin, M. (2008). Paradigma Pendidikan Konstruktivistik Implementasi KTSP dan UU No 14 Tahun 2005 Tentang Guru dan Dosen. Jakarta: GP Press. 